\title{
A Compact Wideband Dual-Polarized Printed Antenna with Coaxial Feeds for TD-SCDMA Application
}

\author{
Yujie Liu, Wei Tang, Yuehe Ge, Guogang Li \\ College of Information Science and Engineering, Huaqiao University, Xiamen, China \\ Email: yuehe@ieee.org, liutld@126.com
}

Received 20 October 2014; revised 25 November 2014; accepted 29 December 2014

Copyright (C) 2015 by authors and Scientific Research Publishing Inc.

This work is licensed under the Creative Commons Attribution International License (CC BY). http://creativecommons.org/licenses/by/4.0/

(c) (i) Open Access

\begin{abstract}
In this article, a low-profile wideband dual-polarized planar printed dipole antenna, fed by coaxial lines, is investigated for the TD-SCDMA operation. The antenna is composed of two printed dipoles, two pairs of feeding coaxial lines and a ground. The single-polarized planar printed rectangular dipole and petal dipole, with the similar configuration, are first studied, exhibiting the potential wideband operation. Two petal dipoles are then cross-arranged to design a dual-polarized planar printed antenna, giving a lower profile and a better bandwidth covering the Chinese TD-SCDMA band (1880 - $2400 \mathrm{MHz}$ ). The dual-polarized antenna is simply excited by two pairs of coaxial feeds. Simulated and measured results show that the antenna achieves a common impedance bandwidth of $42 \%$ at both ports, good isolation of more than $25 \mathrm{~dB}$, stable radiation patterns and the gain of about $7 \mathrm{dBi}$ over the operating bandwidth.
\end{abstract}

\section{Keywords}

Base Station Antenna, Dual Polarization, Petal Type Antenna, TD-SCDMA, Printed Dipole

\section{Introduction}

The population of mobile communication systems is growing continuously. The increasing capacity issue is becoming critical because of the expansion of wireless services and the number of mobile subscribers. The methods to solve this issue include the use of wideband and polarization diversity mobile systems. Wide bandwidth, high isolation and low cross polarization are the normal requirements for mobile antenna systems. In recent years, wideband dual-polarized base-station antennas were developed [1]-[4] for these applications. One of reliable antenna elements for base-station antennas is the dipole antenna with a balanced feed. Printed dipole an- 
tennas and magneto-electric dipole antennas have attracted much attention [5]-[10] for the development of wideband dual-polarized base station antennas. Wide bandwidth and good radiation performance are the common advantages for these antennas. In this paper, a planar petal-shape dipole antenna with coaxial feeding mechanism is developed for wideband applications. Two pairs of such planar printed dipole antennas with two DC grounded coaxial feeds and backed by a PEC ground form a wideband dual-polarized antenna element for base station antennas. The antenna was developed to cover the frequency band for the Chinese self-developed standard Time Division Synchronous Code Division Multiple Access (TD-SCDMA) system, operated at frequency bands (A) 1880 - $1920 \mathrm{MHz}$, (B) 2010 - $2025 \mathrm{MHz}$ and (C) 2300 - $2400 \mathrm{MHz}$. Advantages of this antenna include low profile, wide bandwidth, dual polarization, high isolation and ease to fabricate and mount. Parametric study was performed and a prototype was built and tested to demonstrate the performance of the antenna.

\section{Antenna with Coaxial Feeds Description}

\subsection{Planar Dipole with Coaxial Feeder}

The configuration of the initial planar printed dipole investigated in this work is shown in Figure 1. It is composed of a rectangular printed dipole, a coaxial feeder connected to a SMA connector and a PEC ground. The planar rectangular dipole, with a dimension of $\mathrm{d} \times \mathrm{t}$, is printed on the top surface of a FR4/Epoxy substrate, which is suspended on a PEC ground plane and supported by Nylon poles. The substrate has a height of h1, a dielectric constant of 4.4 and a thickness of $0.8 \mathrm{~mm}$, as shown in Figure 1(a). The substrate and the ground have the dimensions of $\mathrm{L} 1 \times \mathrm{W} 1$ and $\mathrm{L} \times \mathrm{W}$ respectively. The dipole is fed by a coaxial balun. Figure $\mathbf{1 ( b )}$ shows the feeding mechanism. Two coaxial lines are placed between the substrate and the ground. The outer copper shields of both coaxial lines are connected to the PEC ground, as well as the dipole through two metal poles. One of inner copper cores is connected to a $50 \Omega$ SMA connector underneath the ground and a small metallic strip, printed on the top surface of the substrate. Another copper core is an open stub and connected to the other end of the strip and has a length of h2 + ht. Compared to the conventional printed dipole antenna, the two copper cores and the small strip on the top surface of the substrate are served as the balun and the copper shields are the corresponding ground connected to the printed dipole. The antenna has a planar structure and an additional ground to increase the directivity above the ground.

The design of this planar printed dipole antenna with a coaxial feeding is similar to that of a conventional dipole antenna. A $\lambda / 4$ short-circuited conductor is needed to connect one of the $\lambda / 4$ printed strips. The outer conductors or the copper shields of the coaxial line are employed as the $\lambda / 4$ short-circuited conductor. Therefore, the length of the coaxial line, h1, should be about $\lambda / 4$ of the operating frequency. The length of the open copper core, h2, should be about $\lambda_{\mathrm{g}} / 4$ ( $\lambda_{\mathrm{g}}$ is the guided-wavelength in coaxial line) in order for the balun to feed the planar dipole antenna. The dipole length, $\mathrm{d}$, should be about $\lambda_{1} / 4$ ( $\lambda_{1}$ is the wavelength on the FR4 substrate). The antenna is designed for the wireless base station antennas operating at about $2 \mathrm{GHz}$. Based on the design strategy above, the dimensions of the planar dipole antenna are optimized and listed in Table 1. In the design, the parameter h1 and h2 are two important parameters to tune the impedance matching of the antenna. The parameter h1 is normally chosen to be as small as possible, to keep a low profile. The length of the open copper core, h2, can be adjusted for good impedance matching. The simulated VSWRs for h1 = $50 \mathrm{~mm}$ and different h2 values, obtained from commercial software Anoft HFSS, are plotted in Figure 2.

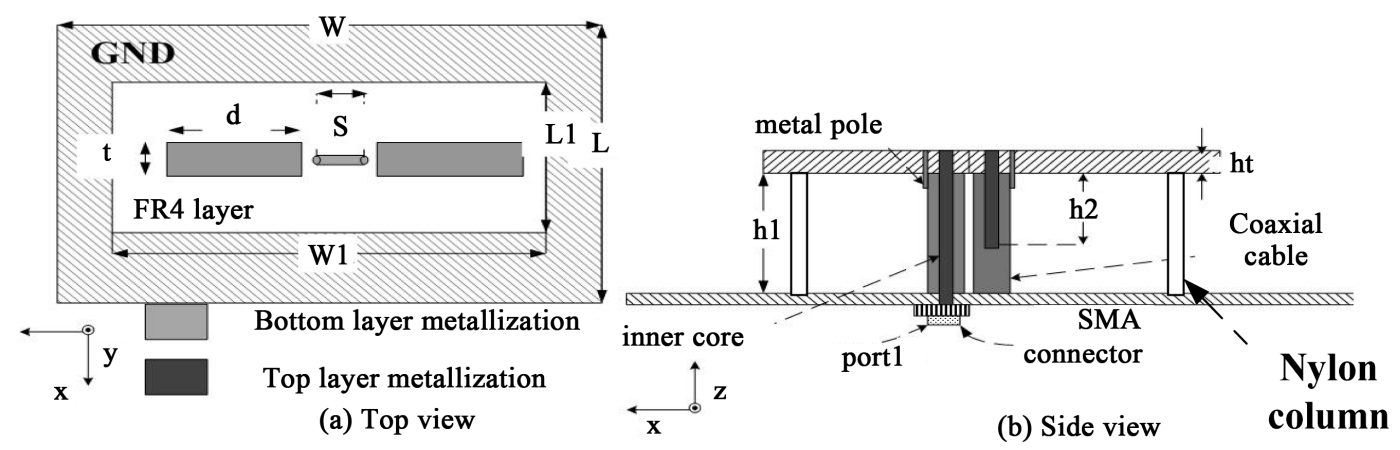

Figure 1. Configuration of the investigated planar printed rectangular dipole. 


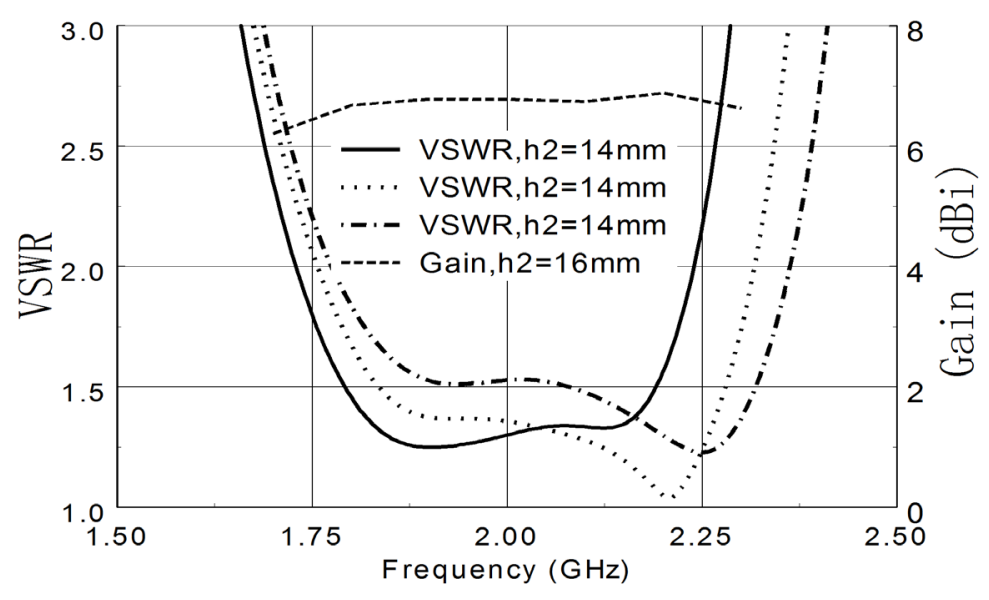

Figure 2. VSWR and realized gain of the planar rectangular dipole antenna.

Table 1. Dimensions of the planar printed rectangular dipole antenna with a coaxial feed (unit: $\mathrm{mm}$ ).

\begin{tabular}{ccccc}
\hline W & L & W1 & L1 & S \\
\hline 150 & 150 & 80 & 40 & 5.2 \\
d & T & h1 & h2 & ht \\
26 & 5 & 50 & 16 & 0.8 \\
\hline
\end{tabular}

As can be seen, adjusting the length of the open copper core can minor tune the operating band and the impedance matching. The simulated realized gain for $\mathrm{h} 2=16 \mathrm{~mm}$, also plotted in Figure 2, is maintained about 6.7 $\mathrm{dBi}$ over the whole operating band, which is determined by VSWR $<2$, ranging from $1.75 \mathrm{GHz}$ to $2.32 \mathrm{GHz}$, about $28 \%$.

\subsection{Petal Dipole with Coaxial Feeder}

Further study on the planar printed dipole antenna with a coaxial feed was carried out and it is found that the bandwidth can be improved by changing the shape of the printed dipole, without compromising the radiation performance. One of the examples is the planar printed dipole with a petal shape. Figure 3 shows the geometry of the petal dipole. It can be seen that the antenna geometry is similar to that in Figure 1, except for the shape of the dipole. The parameters of the petal dipole are optimized and the final dimensions are listed in Table 2 . The simulated VSWR and realized gain are plotted in Figure 4. The bandwidth for VSWR $<2$ is $35 \%$, from 1.74 $\mathrm{GHz}$ to $2.48 \mathrm{GHz}$. Compared to that of the dipole in Figure 1, which is $28 \%$, the bandwidth is improved by $7 \%$. The realized gain is also improved a little, though it slightly decreases with frequency.

\subsection{Dual-Polarized Planar Printed Dipole with Coaxial Feeder}

Dual-polarized dipoles are normally used to develop base station antennas, to reduce the effect of multi-path fading and increase channel capacity in mobile communication systems. Two planar printed petal dipoles are employed in this section to develop a dual-polarized antenna. Figures 5(a)-(c) show the top view, the 3D view and the side view of the configuration of the concerned planar printed antenna, fed by coaxial lines, respectively. Two planar petal dipoles are cross-printed on a substrate and two pairs of coaxial lines are used to feed them. The two petal dipoles have the same dimension but different feeding structures. The configuration of one of the two petal dipole antennas and its feeding mechanism is the same as that shown in Figure 3. Another crossed petal dipole is on the same surface but the coaxial feeding is a little different. As shown in Figures 5(a)-(b), two small metallic strips are cross-printed on the top and the bottom surfaces of the substrate respectively. The copper cores of the two coaxial lines, used to feed the second dipole, are connected to the two ends of the strip on the bottom surface of the substrate and the outer copper shields are connected to the petal dipole through two 


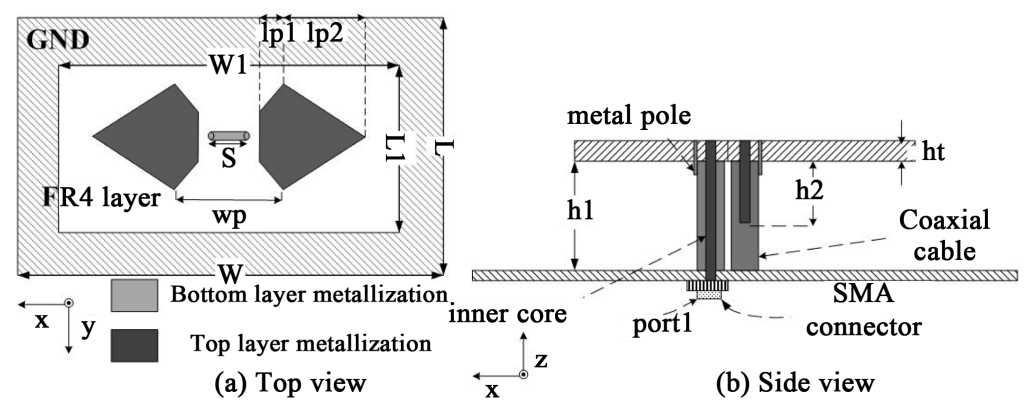

Figure 3. Configuration of the wideband planar printed petal dipole.

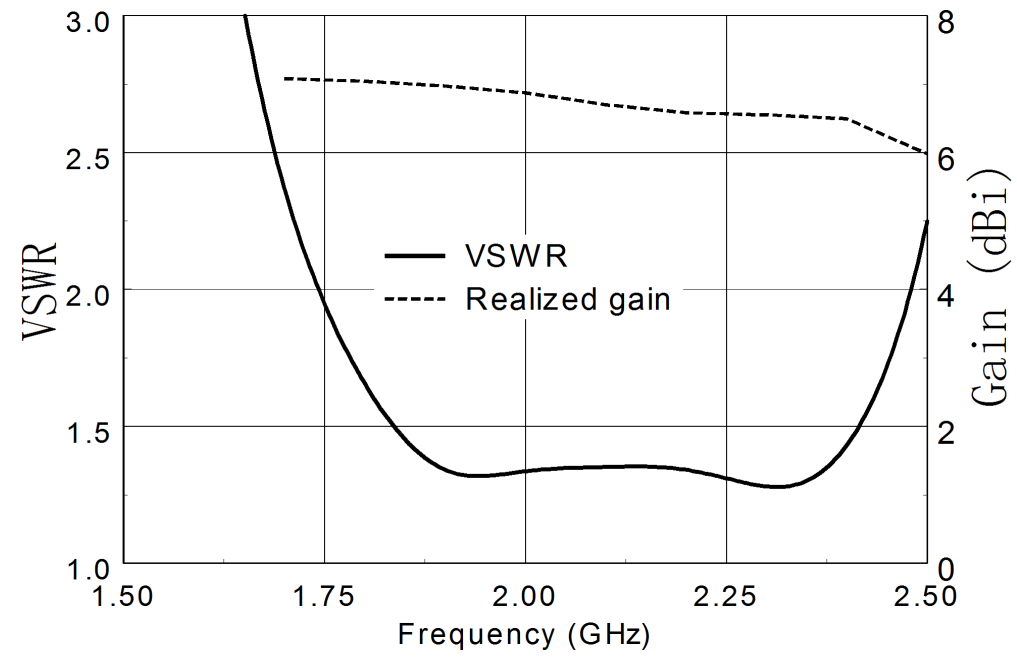

Figure 4. VSWR and gain of the printed petal dipole antenna.

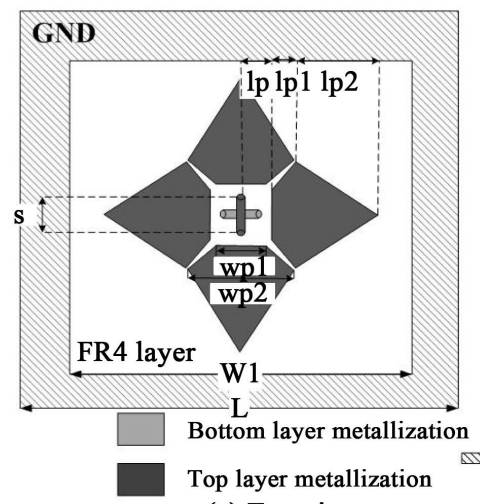

(a) Top view

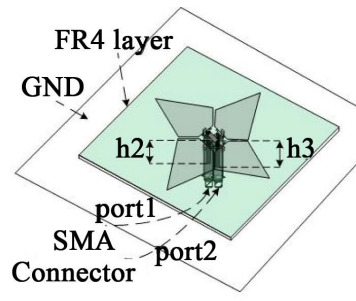

(b) $3 \mathrm{D}$ view

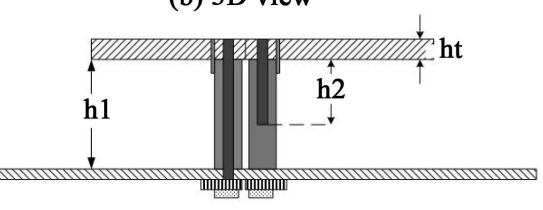

(c) Side view

Figure 5. Geometry of the concerned dual-polarized planar printed antenna.

Table 2. Dimensions of the planar printed petal dipole antenna with a coaxial feed (unit: $\mathrm{mm}$ ).

\begin{tabular}{cccccc}
\hline L & W & L1 & W1 & S & wp \\
\hline 150 & 150 & 40 & 80 & 5.2 & 33.6 \\
lp1 & lp2 & h1 & h2 & ht & \\
12 & 13 & 50 & 20 & 0.8 & \\
\hline
\end{tabular}


metallic poles, as shown in Figure 5(c). Thus, the two dipoles can be cross-arranged and fed by two pairs of coaxial lines, exhibiting dual-polarization performance.

In the design, FR4/Epoxy substrate with the permittivity of 4.4 and a thickness of $1.5 \mathrm{~mm}$ is employed. The height (h1) of the substrate, the lengths of the two open copper cores and the dimensions of the dipoles determine the impedance matching and its operating bandwidth. The target of the design is the wide bandwidth and the low profile of the antenna. Based on the simulation and optimization from HFSS, it is found that the antenna exhibits a better bandwidth and a lower profile, compared to the two single-polarized cases shown in Figure 1 and Figure 3 respectively. The reason might be the strong mutual coupling between the two dipoles. The final optimized dimensions of the dual-polarized design are listed in Table 3. It can be seen that the height (h1) of the substrate is only $32 \mathrm{~mm}$, lower than those in the designs shown in Figure 1 and Figure 3 . The VSWRs of the two ports of the dual-polarized planar printed dipole antenna, calculated using Ansoft HFSS, are plotted in Figure 6. One can see that wide operating bands at the two ports, determined by VSWR $<2$ and ranging from 1.54 $\mathrm{GHz}$ to $2.78 \mathrm{GHz}$ and $1.6 \mathrm{GHz}$ to $2.8 \mathrm{GHz}$ respectively, are obtained. The bandwidths at the two ports are $57.4 \%$ and $54.5 \%$ respectively and both cover the Chinese TD-SCDMA band (1880 - $2400 \mathrm{MHz})$. Compared to those of the single-polarized designs above, which are $28 \%$ and $35 \%$ respectively, the common bandwidth, which is about $54 \%$, is significantly improved, due to the mutual coupling between the two dipoles.

The fabricated prototype for the designed dual-polarized printed dipole was measured using Vector Network Analyzer Agilent E8363C and the measured results are also plotted in Figure 6, for comparison. The measured common bandwidth for the two ports of the antenna are $42 \%$, ranging from $1.76 \mathrm{GHz}$ to $2.68 \mathrm{GHz}$. Figure 7 shows the simulated and measured isolations between the two ports, which are $30 \mathrm{~dB}$ and $25 \mathrm{~dB}$ over the whole operating bandwidth, respectively. The difference between simulations and measurements might come from the difficulty when tuning open copper cores and other unpredicted factors during the fabrication. The realized gain, calculated using Ansoft HFSS and shown in Figure 8, is maintained about $7 \mathrm{dBi}$ over the bandwidth, for both ports. The antenna prototype is also measured and the measured gains for both ports are almost same. Therefore, only one measured gain curve is given in Figure 8. Figure 9 shows the prototype pictures of the proposed dual-polarization planar antenna. The radiation patterns are also measured and plotted in Figure 10. It can be seen that stable radiation patterns at $1.8 \mathrm{GHz}, 2.2 \mathrm{GHz}$ and $2.4 \mathrm{GHz}$ are obtained.

Table 3. Dimensions of the dual-polarized printed antenna (unit: $\mathrm{mm}$ ).

\begin{tabular}{cccccc}
\hline L & W1 & wp1 & wp2 & lp & lp1 \\
\hline 160 & 80 & 8 & 24 & 4.8 & 7.5 \\
lp2 & h1 & h2 & h3 & ht & S \\
22.5 & 32 & 16 & 21.5 & 1.5 & 5.2 \\
\hline
\end{tabular}

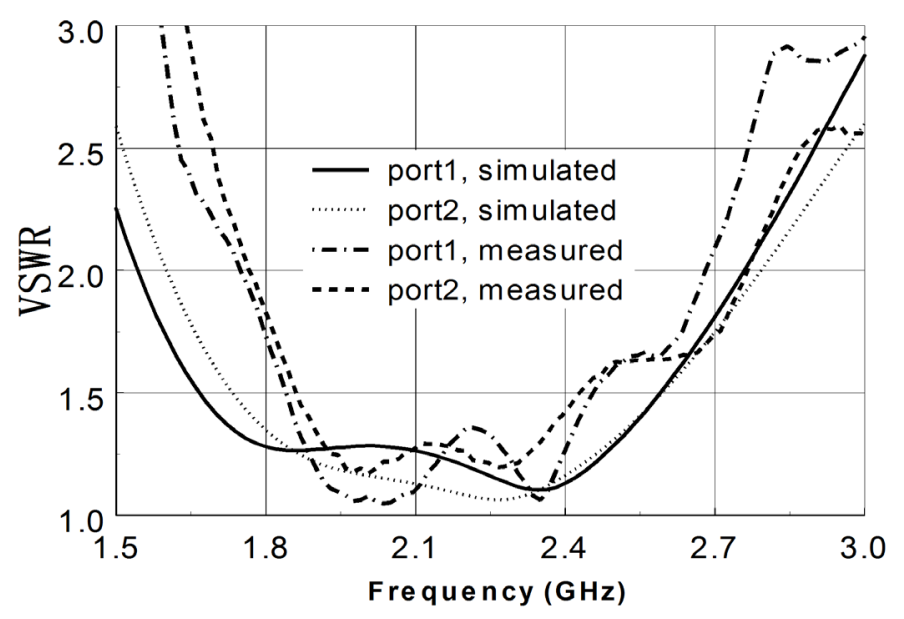

Figure 6. Measured and simulated VSWRs for the dual-polarized planar printed antenna excited by coaxial lines. 


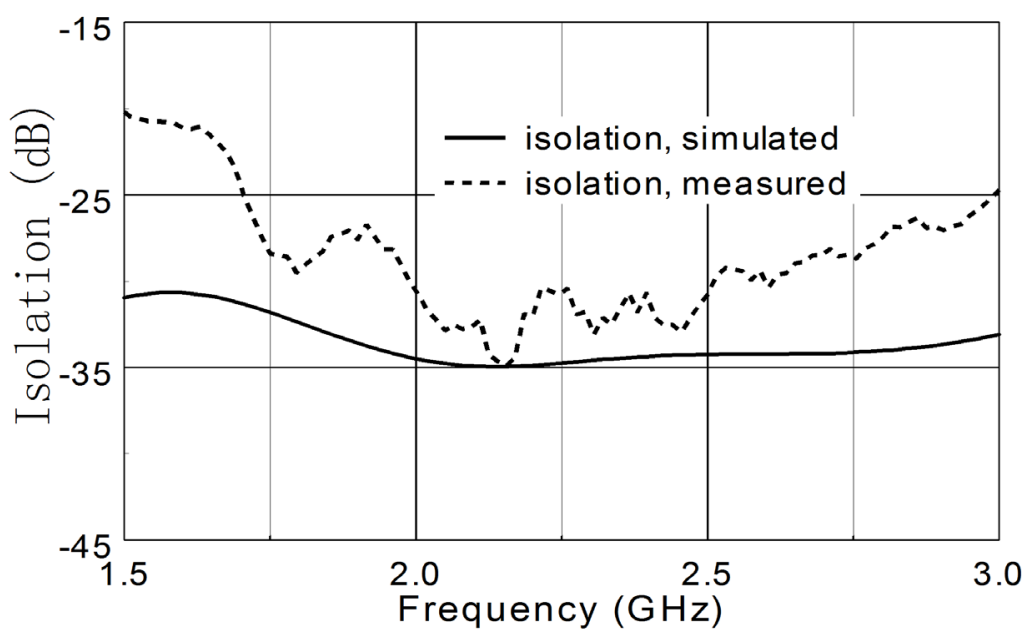

Figure 7. Measured and simulated isolation for the dual-polarized planar printed antenna excited by coaxial lines.

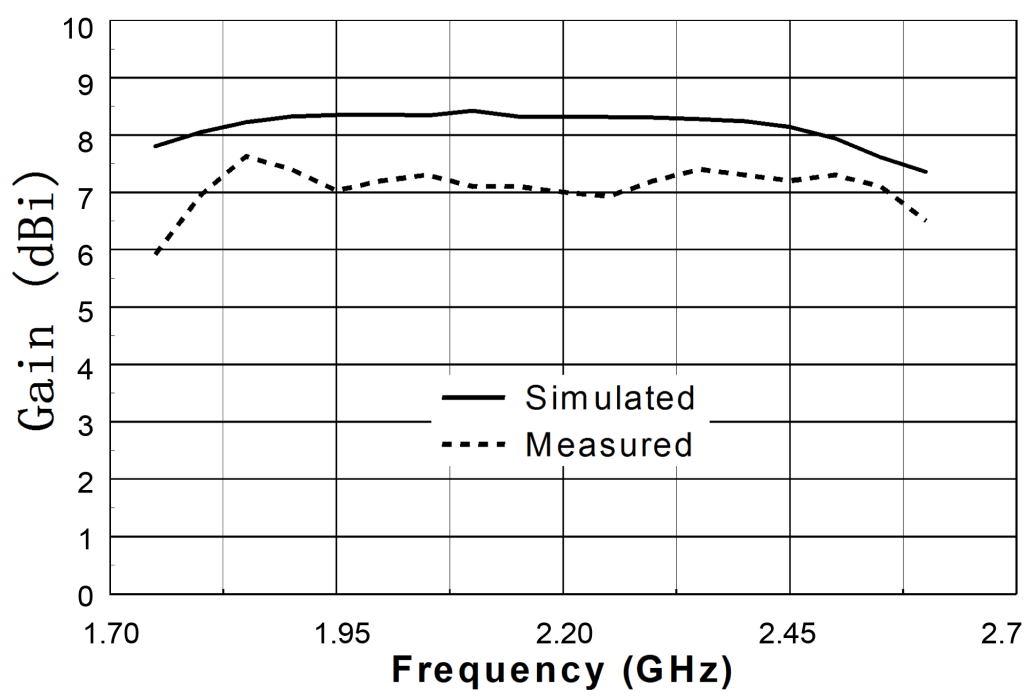

Figure 8. Gain of the dual-polarized planar printed antenna excited by co-axial lines.

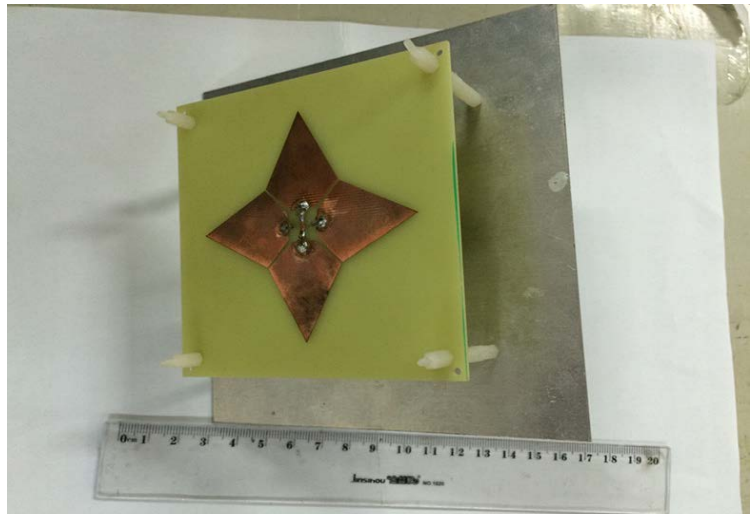

(a)

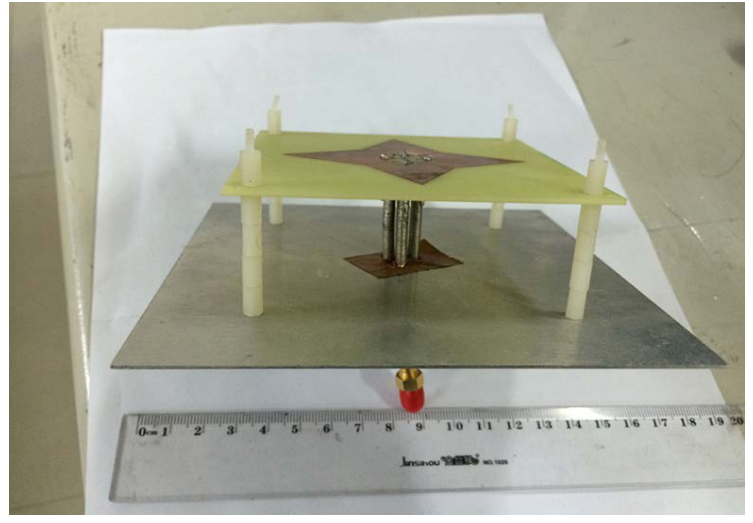

(b)

Figure 9. The photographs of the antenna prototype: (a) top view; (b) side view. 

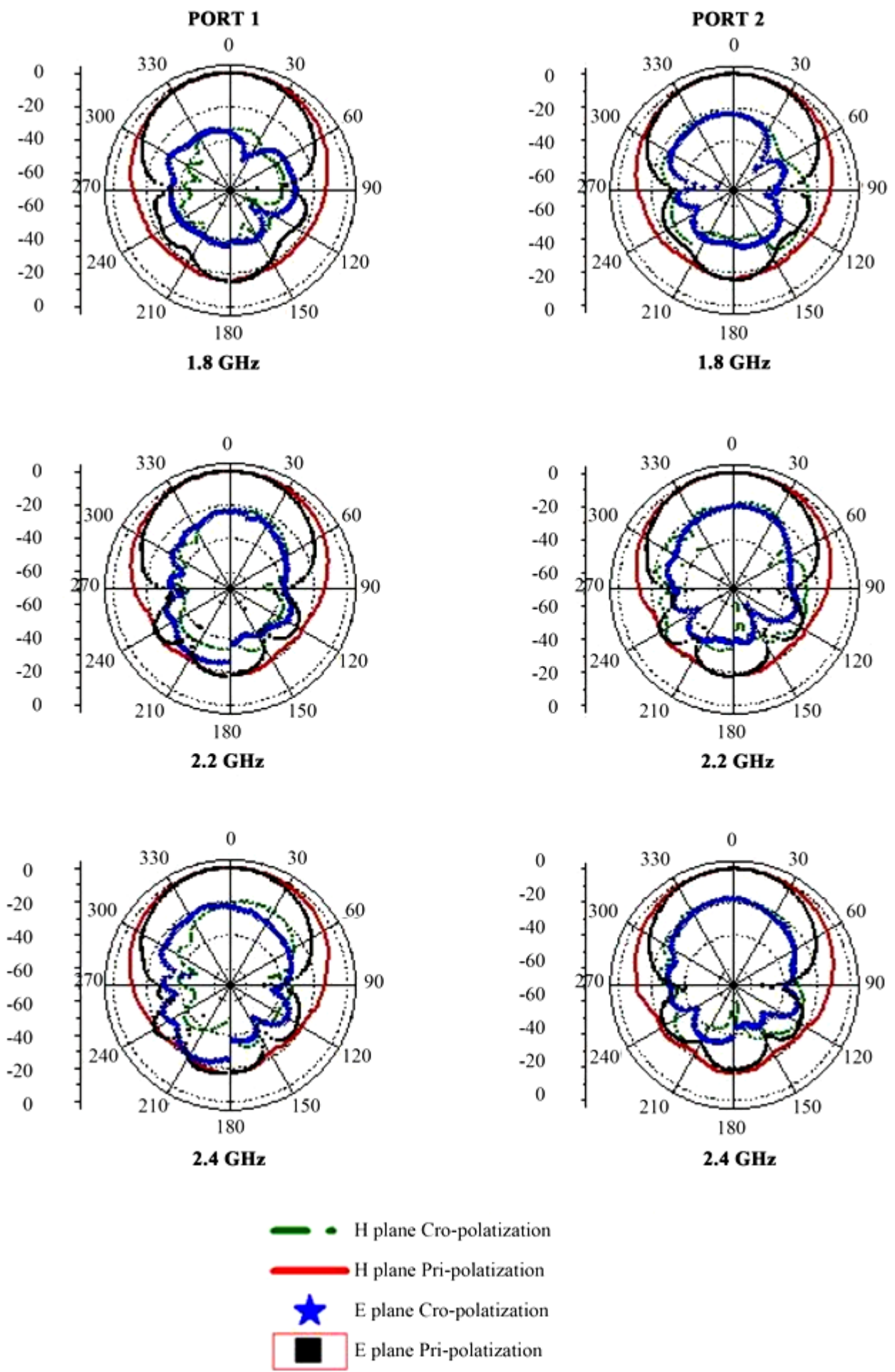

Figure 10. Measured radiation patterns of the dual-polarized planar printed antenna in $\mathrm{E}$ and $\mathrm{H}$ planes at $1.8 \mathrm{GHz}, 2.2 \mathrm{GHz}$ and 2.4 GHz, for Port 1 and Port 2, respectively.

\section{Conclusion}

It has been demonstrated theoretically and experimentally that the planar printed dipole with a DC ground and a coaxial feeding structure is able to be designed for wideband operations. A planar printed rectangular dipole and 
a petal dipole, with such configuration, have achieved bandwidths of $28 \%$ and $35 \%$ respectively. Two printed petal dipoles are then cross-printed on a FR4/Epoxy substrate, fed by two pairs of coaxial lines and backed by a PEC ground, forming a low-profile dual-polarized antenna for the TD-SCDMA operation. Due to the mutual coupling, the antenna has a lower profile (about $0.21 \lambda$ at $2 \mathrm{GHz}$ ), a wider common bandwidth (42\%), stable radiation patterns over the whole bandwidth and a stable gain of about $7 \mathrm{dBi}$. Additional advantages include simple structure, ease to fabricate, install, and be arrayed for TD-SCDMA base station antenna.

\section{Acknowledgements}

This research was supported by the centre university special funding project (JB-ZR1144), China, and Natural Science Foundation of Fujian Province (2011J01351), China, the Tongjiang Scholars Program, Fujian province, China, the Start-Up Program (11BS301) from Huaqiao University, China, Natural Science Foundation of Fujian Province (2012J01276), China, Xiamen Major Science and Technology Project (3502Z20131019), and Quanzhou Science and Technology Project (Z1424008), Quanzhou, Fujian province, China.

\section{References}

[1] Wong, H., Lau, K.L. and Luk, K.M. (2004) Design of Dual-Polarized L-Probe Patch Antenna Arrays with High Isolation. IEEE Transactions on Antennas and Propagation, 52, 45-52. http://dx.doi.org/10.1109/TAP.2003.822402

[2] Wu, B.Q. and Luk, K.M. (2009) A Broadband Dual-Polarized Magneto-Electric Dipole Antenna with Simple Feeds. IEEE Antennas and Wireless Propagation Letters, 8, 60-63. http://dx.doi.org/10.1109/LAWP.2008.2011656

[3] Secmen, M. and Hizal, A. (2010) A Dual-Polarized Wide-Band Patch Antenna for Indoor Mobile Communication Applications. Progress in Electromagnetics Research (PIER), 100, 189-200. http://dx.doi.org/10.2528/PIER09112607

[4] Lian, R.N. and Zheng, S.F. (2014) A Single-Layer Wideband Dual-Polarized Antenna with High Isolation. Progress In Electromagnetics Research C, 49, 115-122. http://dx.doi.org/10.2528/PIERC14031904

[5] Adrian and Schaubert, D.H. (1987) Dual Aperture-Coupled Microstrip Antenna for Dual or Circular Polarization. Electronics Letters, 23, 1226-1228. http://dx.doi.org/10.1049/el:19870854

[6] Zhou, Z.W., Yang, S.W. and Nie, Z.P. (2007) A Novel Broadband Printed Dipole Antenna with Low Cross-Polarization. IEEE Transactions on Antennas and Propagation, 55, 3091-3093. http://dx.doi.org/10.1109/TAP.2007.908570

[7] Li, R.L., Wu, T. and Pan, B. (2009) Equivalent-Circuit Analysis of a Broadband Printed Dipole with Adjusted Integrated Balun and an Array for Base Station Applications. IEEE Transactions on Antennas and Propagation, 57, 21802184. http://dx.doi.org/10.1109/TAP.2009.2021967

[8] Vallecchi, A. and Gentilli, G.B. (2005) Design of Dual-Polarized Series-Fed Microstrip Arrays with Low Losses and High Polarization Purity. IEEE Transactions on Antennas and Propagation, 53, 1791-1798. http://dx.doi.org/10.1109/TAP.2005.846732

[9] Huang, Y.-H. and Zhou, S.-G. (2013) Compact and Wideband Dual-Polarized Antenna with High Isolation for Wireless communication. Progress in Electromagnetics Research Letters, 38, 171-180. http://dx.doi.org/10.2528/PIERL13020102

[10] Moradi, K. and Nikmehr, S. (2012) A Dual-Band Dula-Polarized Microstrip Array Antenna for Base Stations. Progress in Electromagnetics Research, 123, 527-541. http://dx.doi.org/10.2528/PIER11111610 
Scientific Research Publishing (SCIRP) is one of the largest Open Access journal publishers. It is currently publishing more than 200 open access, online, peer-reviewed journals covering a wide range of academic disciplines. SCIRP serves the worldwide academic communities and contributes to the progress and application of science with its publication.

Other selected journals from SCIRP are listed as below. Submit your manuscript to us via either submit@scirp.org or Online Submission Portal.
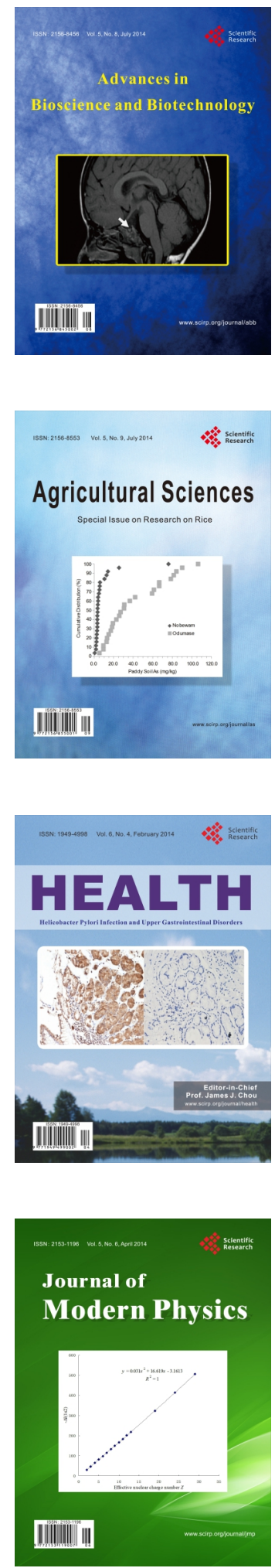
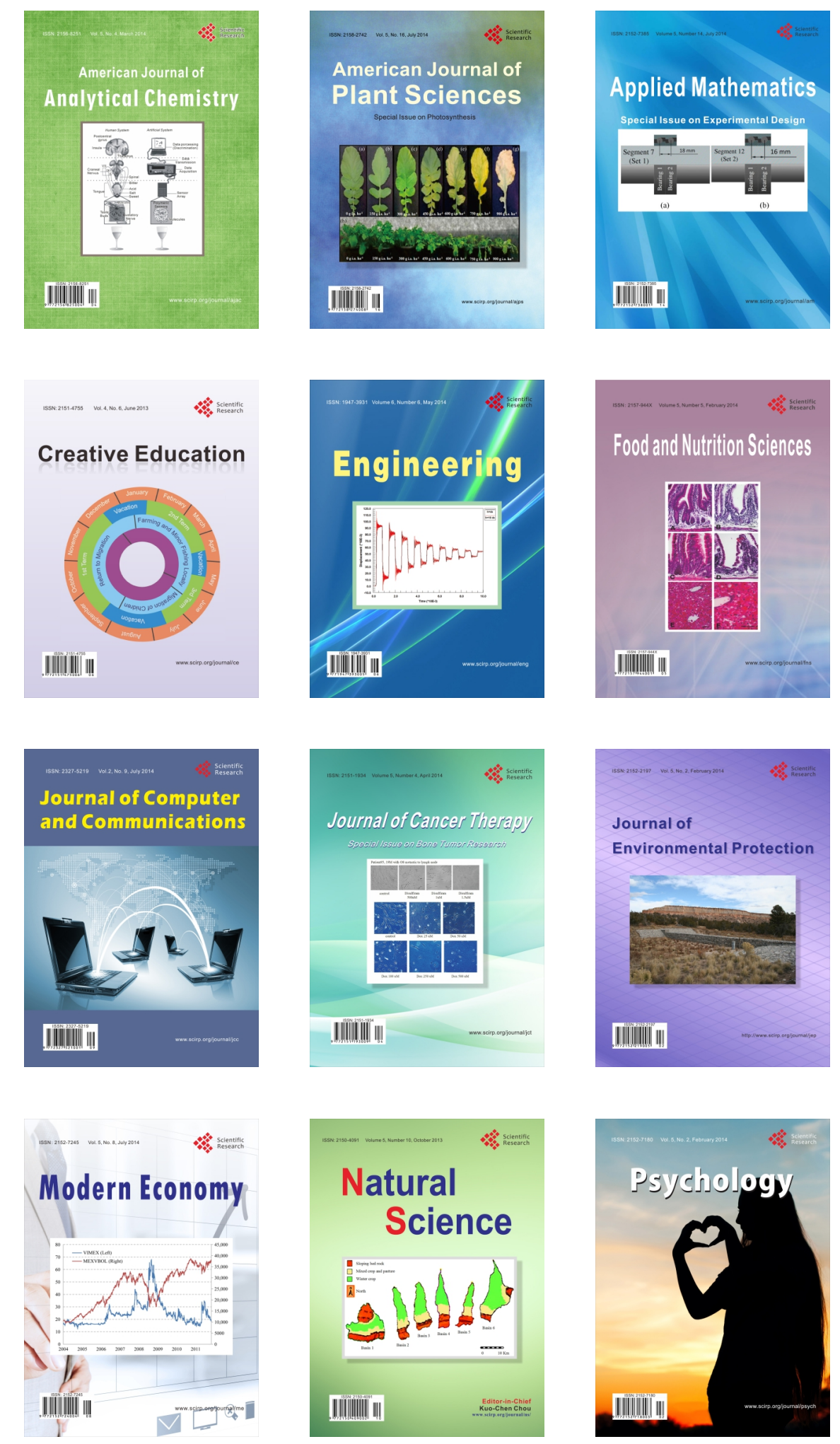